OPEN ACCESS

Edited by:

Guangyu Wang,

University of British Columbia,

Canada

Reviewed by:

Chen Wang,

South China Botanical Garden,

Chinese Academy of Sciences (CAS),

China

Charles Van Rees,

University of Georgia, United States

Songhe Zhang,

Hohai University, China

*Correspondence:

Xiqiang Song

songstrong@hainanu.edu.cn

Mingxun Ren

renmx@hainanu.edu.cn;

415827543@qq.com

Specialty section:

This article was submitted to

Conservation and Restoration

Ecology,

a section of the journal

Frontiers in Ecology and Evolution

Received: 30 March 2021

Accepted: 08 October 2021

Published: 18 November 2021

Citation:

Shen Y, Lei J, Song X and Ren M (2021) Annual Population Dynamics and Their Influencing Factors for an Endangered Submerged Macrophyte

(Ottelia cordata).

Front. Ecol. Evol. 9:688304. doi: 10.3389/fevo.2021.688304

\section{Annual Population Dynamics and Their Influencing Factors for an Endangered Submerged Macrophyte (Ottelia cordata)}

\author{
Yichun Shen ${ }^{1}$, Jinrui Lei ${ }^{2}$, Xiqiang Song ${ }^{1 *}$ and Mingxun Ren ${ }^{3 *}$ \\ 1 Key Laboratory of Genetics and Germplasm Innovation of Tropical Special Forest Trees and Ornamental Plants, School \\ of Forestry, Ministry of Education, Hainan University, Haikou, China, ${ }^{2}$ Hainan Academy of Forestry, Haikou, China, ${ }^{3}$ Center \\ for Terrestrial Biodiversity of the South China Sea, Hainan University, Haikou, China
}

Due to wetland loss, Ottelia cordata (O. cordata, Wallich) Dandy has been categorized as an endangered species on the List of Key Protected Wild Plants in China. Quantifying the relative importance of demographic (i.e., growth, survival, and reproduction) and habitat preference traits on the population dynamics (abundance) of $O$. cordata could guide how to develop the best recovery strategies of $O$. cordata, yet currently, there are no studies that investigate this. By monitoring monthly changes in $O$. cordata abundance and demographic traits (plant height, leaf area, flower sex ratio, and seed number) that were highly correlated with growth rate, photosynthetic rate, and water depth, we identified several relationships. Linear mixed-effect models and variance partition quantified the specific effects of four demographic traits and water depth on O. cordata abundance in three habitat types (paddyfield, stream, and spring). The linear mixed-effect models indicate that among the four demographic traits, height could be significantly positively correlated to abundance in all three habitat types. In contrast, other three traits (leaf area, sex ratio, and seed numbers) were non-significantly associated with abundance across each habitat. Height was determined by water depth, so water depth rather than photosynthetic rate and reproduction rate may promote the development and recovery of $O$. cordata populations. Variance partition results showed that water depth mediated the positive influence of growth rate on the abundance of $O$. cordata in the living habitats (paddyfield and spring). In contrast, water depth but not growth rate determined the abundance of $\mathrm{O}$. cordata in the living habitat (stream). However, water depth had a significantly negative impact on the abundance of $O$. cordata in stream habitats, likely because all of the streams were shallow. Altogether, in the short term for avoiding the potential harm or even extinction of $O$. cordata, keeping appropriate water depth or transplanting $O$. cordata to spring should be an effective strategy because the water 
is not only deep enough but also clear in spring habitats. Additionally, water turbidity was shown to affect the density of $O$. cordata growth, wherein $O$. cordata was sparsely distributed when turbidity was high. Therefore, in the long run, to make the population gradually recovery, it will be necessary to restore the degraded wetland. This could be accomplished by reducing water pollution and removing sludge to reduce turbidity and increase hydrological connectivity.

Keywords: abundance, demographic traits, linear mixed-effect model, monthly variation, conservation strategy

\section{INTRODUCTION}

Ottelia cordata (O. cordata, Wallich) Dandy, distributed in China, Cambodia, Myanmar, and Thailand (Wang et al., 2010), is a submerged dioecious macrophyte that is insect-pollinated and shows leaf dimorphism in submerged and floating leaves. Found in clear and slowly flowing water, full lifecycle of O. cordata is inseparable from water, though flowering takes place on the water surface. Historically, O. cordata was widely distributed in the whole Hainan province, located in the southernmost part of China, at the northern edge of the tropics. Hainan province has a tropical monsoon climate with abundant rainfall from May to November followed by a dry season. The vegetation is mainly tropical monsoon rain forest. Due to wetland destruction (e.g., cutting forest for planting, production and domestic sewage discharge), O. cordata can only be found in part of northern Hainan Province (Haikou city, Ding'an County, and Chengmai County), China (Figure 1a), close to $90 \%$ of the distribution points are located in Haikou, so it has a very narrow distribution. In recent years, multiple factors, such as water eutrophication and wetland destruction, have resulted in the loss of many $O$. cordata populations and a significant reduction in its range (Wang et al., 2019). According to the observation of the research group of authors, the distribution points of $O$. cordata were decreased from 42 points to 38 points, and the number O. cordata was decreased by about 11\% between 2017 and 2020. Given these trends, $O$. cordata has been categorized as an endangered species in the List of Key Protected Wild Plants in China (Zhang et al., 2019). To protect and recover O. cordata, several wetland reserves, such as the Yangshan Wetland Reserve and Changwangxi Wetland Reserve, have been established in Hainan Province (Wang et al., 2019). However, without knowing local population dynamics and their potential influencing factors, it is very difficult to develop accurate and effective protection strategies to save this endangered species.

Although $O$. cordata has been listed as endangered plant species in China, there are no specific evaluation criteria judging its endangered degree. It has been shown that without knowing the plant species population dynamics and demographic traits, any evaluation of endangered degree is essentially guesswork (Tear et al., 1993; Schemske et al., 1994; Neel et al., 2012). Moreover, population dynamics (e.g., abundance) of the population should be determined using demographic traits that are highly associated with growth and reproduction (Davies et al., 2000; Rytwinski and Fahrig, 2012; Soudzilovskaia et al., 2013; Curtis et al., 2015). Therefore,
O. cordata population dynamics and demographic traits were measured to determine which demographic characteristics influence population dynamics, thereby shedding light on the potential influencing the endangered degree. Using these population dynamics and demographic traits for O. cordata to understand the determinants of $O$. cordata abundance dynamics, effective recovery strategies can be developed (Wang et al., 2010).

Since $O$. cordata is an annual submerged macrophyte, its population dynamics should be easy to measure as it only requires monthly monitoring across its population distribution within a 1-year period. To be the best of our knowledge, the whole genome of $O$. cordata and its response to $\mathrm{CO}_{2}$ addition have been reported (Wang et al., 2019; Zhang et al., 2019; Huang et al., 2020), while currently there are no reports on its population dynamics and demographic traits. As a result, it is very difficult to develop effective and suitable recovery strategies to better protect $O$. cordata. Therefore, in this study, we monitored the monthly variation in population dynamic (i.e., abundance) and several key demographic traits (i.e., height, leaf area, the ratio of numbers of male and female flowers, and seed numbers) in all possible distributions of $O$. cordata that were highly associated with growth, photosynthesis rate reproduction of submerged macrophyte over a 1-year period. For example, several studies indicate that height and leaf are highly associated with growth and photosynthesis rate for submerged macrophyte (Fu et al., 2014; Huang et al., 2020; Zhang et al., 2020). Additionally, the ratio of numbers of male and female flowers and seed numbers are highly associated with the reproductive ability of submerged macrophytes (Xu et al., 2015; Liu et al., 2017; Zhang et al., 2020). It has also been widely noted that water depth is a key factor affecting the growth, reproduction, and re-establishment of submerged macrophyte populations (Nõges and Nõges, 1999; Dong et al., 2014). Deeper water may induce lower light intensity, however, increased water pressure and unstable temperature and sediment at such depths may not favor increased growth and reproduction for submerged macrophytes (Philbrick and Les, 1996; Kosuge et al., 2013). Similarly in very shallow water depth, light intensity and temperature at shallow depths may limit the growth and reproduction of submerged macrophytes (Søndergaard et al., 2010; Zhu et al., 2012; Li et al., 2017). Taken altogether, it may be that water depth is a key regulating factor. Therefore, we aimed to use the measured monthly variation in abundance, demographic traits, and water depth to quantify, (1) monthly variations of abundance, demographic traits, and water depth for O. cordata; (2) whether the key demographic characteristic or water depth was the determining 


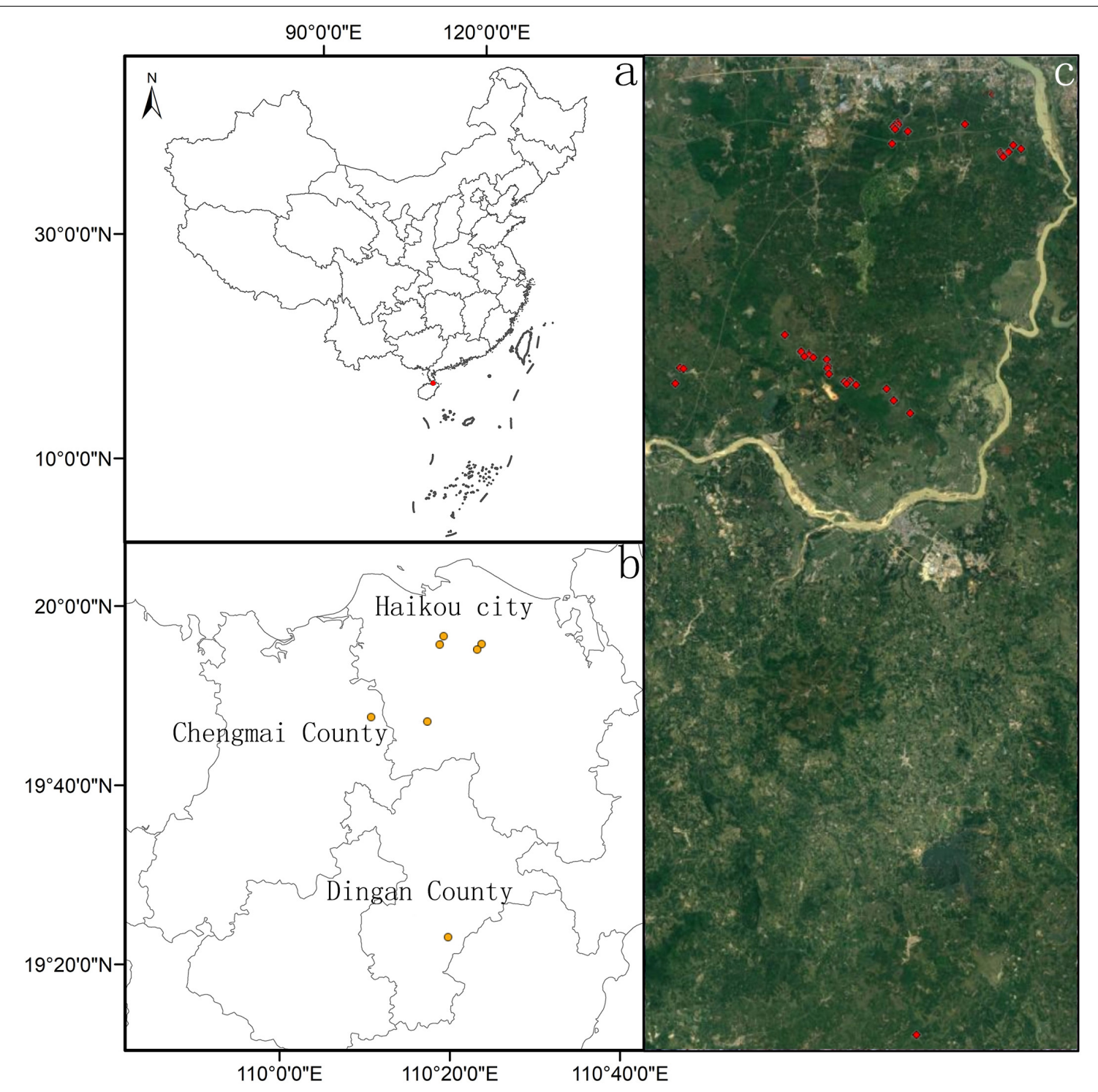

FIGURE 1 | Topographic map of all spatial distributions of Ottelia cordata (c) in our several study sites (five in Haikou city, one in Chengmai County, and one in Ding'an County) (b) in Hainan province, China (a). Red symbols indicate all distribution points, and yellow symbols represent sample plots.

factor influencing abundance for O. cordata by investigating the interrelationships among these variables. We hypothesize that water depth and some demographic characteristics (height, sex ratio, or seed numbers) could affect the abundance of O. cordata, and their ability to predict $O$. cordata abundance may be different.

\section{MATERIALS AND METHODS}

\section{Study Site}

We determined all the distribution points for O. cordata by means of unmanned aerial vehicle and field investigation. Dji Mavic Air 2 UAV (SZ DJI Technology Co., Ltd. Shenzhen, China) was used for the investigation, with a flight altitude of $10-20 \mathrm{~m}$. In the area around the distribution point of $O$. cordata or in the area where
O. cordata may be distributed, the image accuracy could reach the centimeter level, then confirmed the suspected point by field investigation. Finally, we found a total of 38 distribution points (Figure 1c), one of which was located in Longmen Town, Ding'an County $(19.386458 \mathrm{~N} ; 110.329212 \mathrm{E})$, and three of which were located in Yongfa Town, Chengmai County (19.7872-19.7963N; 110.1748-110.1770E), and the remaining 34 sites were located in Yangshan Wetland Multi-functional Reserve of Haikou City (19.7556N-19.9682N, 110.2333E-110.4070E; Figure 1a).

The distribution areas are divided into the rainy season and dry season. The rainy season was distributed from June to November, and the dry season was distributed from December to April. The average annual precipitation in this region was about $1,966-2,067 \mathrm{~mm}, 70 \%$ of which occurs in the rainy season. The annual average evaporation was 1,763-1,843 $\mathrm{mm}$. 
Across this distribution, the water quality was good with clear water observed at about three-quarters of the total sites, and only a small part of the water with muddy substrate had higher turbidity. There were mainly three habitat types: stream, paddyfield, and spring. The stream type was accounted for about $70 \%$ of sites, the paddyfield type was accounted for about $20 \%$ of sites, and there were only two springs (but the number of O. cordata in spring accounts for about $20-25 \%$ of the total). The water flow speed was gentle with the stream speed at less than $0.5 \mathrm{~m} / \mathrm{s}$ and the springs and paddy fields with a flow rate below $0.1 \mathrm{~m} / \mathrm{s}$. The substrates of the water body were sandy, muddy, or a mixture of the two; sand-mud mixture accounted for about half of the distribution sites. The springs sediment was mainly sandy or having a little mud in some areas. The substrate of paddyfield was mainly muddy, and a few distribution spots were mud-sand mixture. However, there were three types of sediment in streams, and the proportion difference was not obvious. The turbidity of springs and paddyfields was lower, the turbidity of streams with different substrates types varied greatly, among which muddy basement had the highest turbidity, and the sand basement had the lowest turbidity. The chemical oxygen demand (COD) of all water bodies was less than $13.0 \mathrm{mg} / \mathrm{L}$, the springs water was the lowest, and the COD was less than $1.5 \mathrm{mg} / \mathrm{L}$. The total phosphorus (TP) of all water bodies was less than $0.08 \mathrm{mg} / \mathrm{L}$. Other indices were also up to the water standard of class II (or I), except total nitrogen (TN) was between 7.0 and 12.0.

\section{Field Sampling}

Seven sites were selected as sample plots based on the area, the number of plants, distribution distance, habitat type, and water bottom material and at least two sample sites for each habitat (three for streams because there are lots), then seven sites were selected as sample plots, which covered different types and population characteristics of the distribution of $O$. cordata. They were, respectively, Yufucun paddyfield, Changwangxi paddyfield, stream of Nayang Village, stream of Chengmai Yongfa Town, stream of Yangshan forest, Xihu Niang Temple Spring, and Ding'an Cold Spring (Table $\mathbf{1}$ and Figure 1b). O. cordata was an annual plant species, so we studied its population dynamics for a year. Based on our preliminary observation, O. cordata blooms every 2-3 months, therefore, sampling was conducted in 6 months (January, March, May, July, September, and November) in 2020 to quantify variations in O. cordata population dynamics (monthly variation in abundance), its functional traits, and water depth. In each month, in each of 41 sites, five $1 \mathrm{~m} \times 1 \mathrm{~m}$ plots $\left(1 \mathrm{~m}^{2}\right.$ area) were randomly arranged to measure abundance, four traits (height, leaf area, the ratio of numbers of male flower, and numbers of female flower) and water depth every day to calculate average abundance, traits, and water depth for the corresponding month.

\section{Trait Measurement}

Individual leaf area $\left(\mathrm{cm}^{2}\right)$ was calculated from the leaf scans using Image-Pro Plus (IPP) 6.0 (Media Cybernetics, Inc., Silver Spring, $\mathrm{MD}$, United States). We measured the height from the root to the stem, numbers of male and female flowers, and seeds in each individual in each of the five $1 \mathrm{~m} \times 1 \mathrm{~m}$ plots. We then calculated the ratio of numbers of male and female flowers (O. cordata is dioecious, but according to our observation of each flower open only 1 day, it was the sex ratio of flowers rather than the sex ratio of plants that affected the population dynamics, so the sex ratio of flowers was used in this study).

\section{Statistical Analysis}

We first quantify monthly variations in abundance, four functional traits, and water depth. Then we tested whether the four traits and water depth were significantly correlated with abundance for $O$. cordata. Since our study design was hierarchical, with three different living habitat types (paddyfield, stream, and spring), we used linear mixed-effects models using maximum likelihood with the R package "lme4" (Bates et al., 2014). For each trait and the water depth, we used the model: [abundance $\sim$ trait/water depth + (1| living habitat type)] with trait/water depth and living habitat type as the predictor of abundance and random effect, respectively. Finally, we used a variance partitioning analysis to quantify the relative contribution of traits and water depth to abundance for using the function "varpart" in the "vegan" R package (Oksanen et al., 2016). Specifically, abundance with traits and water depth as explanatory variables could be divided into four complementary components: (a) "purely traits," variance explained by traits alone; (b) "shared traits and water depth," variance explained by both traits and water depth; (c) "purely water depth," variance explained by water depth alone; and (d) "unexplained residual variation" (Legendre et al., 2009; Zhang et al., 2018a). For each of the three living habitat types, variance partitioning was done separately.

\section{RESULTS}

Abundance for $O$. cordata showed a clear monthly variation, with the highest abundance occurring in November or January in paddyfield and spring habitats, but from September to November for the stream habitat. The lowest abundance came up from March to May (Figure 2). Similarly, the four demographic traits (height, leaf area, the ratio of numbers of male and female flowers, and seed numbers) for O. cordata also demonstrated clear monthly alteration. However, only height described similar monthly variations to those for abundance. Water depth also showed consistent monthly alterations with those for abundance, but monthly variations for water depths in the stream were much lower than those for paddyfield and spring (Figure 2).

The linear mixed-effect model results indicated that the slopes of the relationships between species abundance and height and abundance and water depth had significantly $(P<0.05)$ across the three living habitat types (Table 2 and Figure 3). For instance, height was significantly correlated with abundance in all three living habitat types (Table 2 and Figure 3). In contrast, water depth was significantly and positively associated with abundance in paddyfield and spring habitats, but was significantly and negatively related to abundance in stream habitats (Table 2 and Figure 3). However, the slopes of the relationships between abundance and functional traits did not change significantly 
TABLE 1 | Characteristics of the Ottelia cordata sample area (2020.01-2020.12).

\begin{tabular}{|c|c|c|c|c|c|c|c|}
\hline The sample name & $\begin{array}{l}\text { Latitude and } \\
\text { longitude }\end{array}$ & $\begin{array}{l}\text { Sample } \\
\text { size }\left(m^{2}\right)\end{array}$ & $\begin{array}{c}\text { Number of } \\
\text { plant }\end{array}$ & Habitat & Water quality & $\begin{array}{l}\text { Bottom } \\
\text { material }\end{array}$ & Remarks \\
\hline Yufucun paddyfield & $\begin{array}{l}110.38479 \mathrm{E} \\
19.928589 \mathrm{~N}\end{array}$ & 800 & $9-520$ & Paddyfield & $\begin{array}{l}\text { Clear, } \\
\text { turbidity } \leq 3 \\
\text { NTU }\end{array}$ & Mud & $\begin{array}{l}\text { O. cordata was } \\
\text { cleaned when } \\
\text { planting rice }\end{array}$ \\
\hline Changwangxi paddyfield & $\begin{array}{l}110.28572 \mathrm{E} \\
19.78905 \mathrm{~N}\end{array}$ & 1,200 & $820-1,300$ & Paddyfield & $\begin{array}{l}\text { Clear, } \\
\text { turbidity } \leq 3 \\
\text { NTU }\end{array}$ & Sand-mud & \\
\hline Stream of Chengmai Yongfa Town & $\begin{array}{c}110.17700 \mathrm{E} \\
19.79633 \mathrm{~N}\end{array}$ & 60 & $10-30$ & Stream & $\begin{array}{l}\text { Some turbid, } \\
\text { turbidity } \leq 15 \\
\text { NTU }\end{array}$ & Mud & $\begin{array}{l}\text { The plant has been } \\
\text { falling, in danger of } \\
\text { disappearing }\end{array}$ \\
\hline Stream of Yangshan forest & $\begin{array}{c}110.31528 \mathrm{E} \\
19.94387 \mathrm{~N}\end{array}$ & 120 & $520-1,100$ & Stream & $\begin{array}{l}\text { Very clear, } \\
\text { turbidity } \leq 1 \\
\text { NTU }\end{array}$ & Sand & \\
\hline Ding'an Cold Spring & $\begin{array}{c}110.32921 \mathrm{E} \\
19.38646 \mathrm{~N}\end{array}$ & 1,000 & $900-1,500$ & Spring & $\begin{array}{l}\text { Very clear, } \\
\text { turbidity } \leq 0.5 \\
\text { NTU }\end{array}$ & Sand & \\
\hline
\end{tabular}

Water quality description: Very clean, everything at the bottom of the water is visible; Clean, most things at the bottom of the water can be seen; Some turbidity, most things at the bottom of the water cannot be seen.

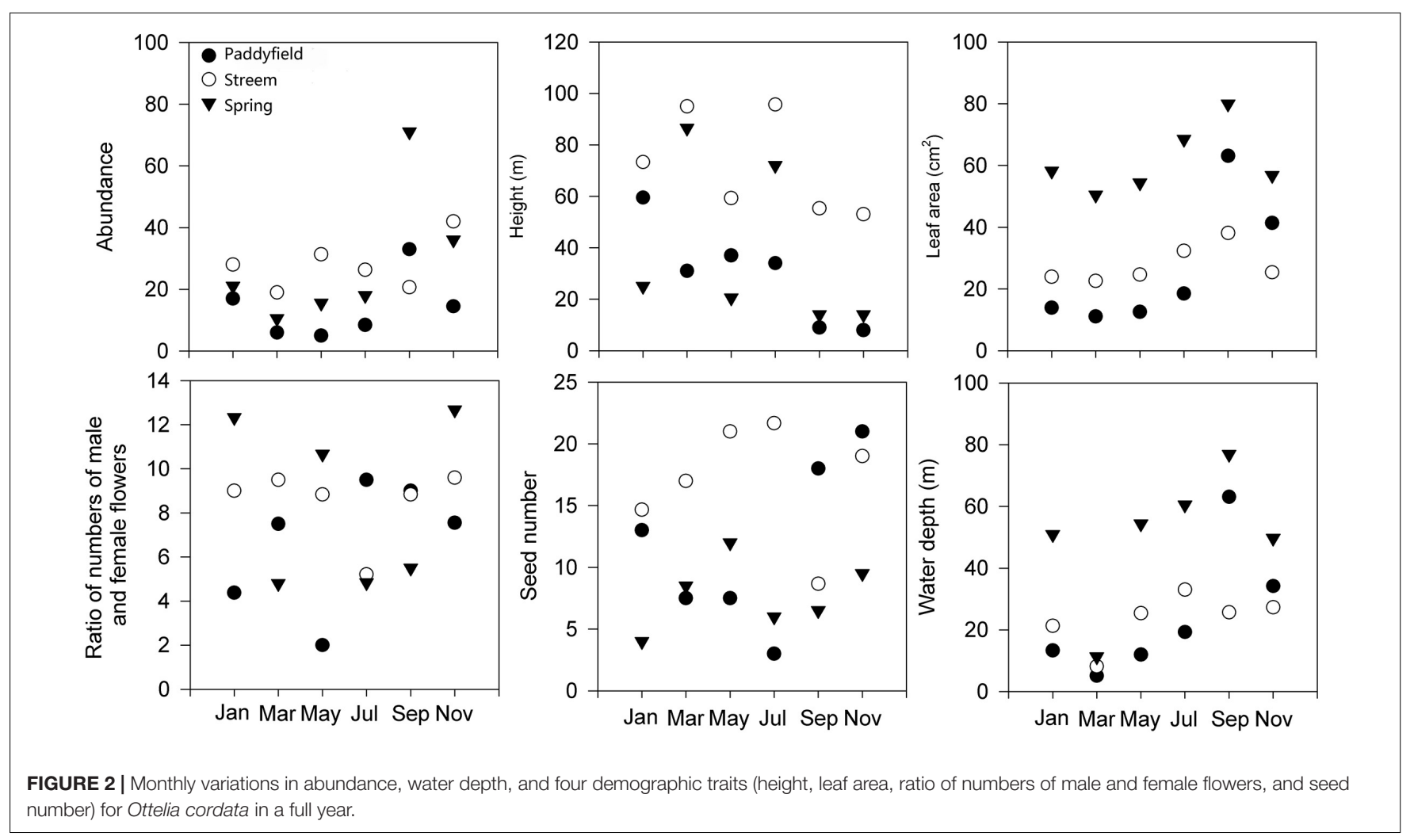

across $(P>0.05$; Table 2 and Figure 3). Additionally, variance partitioning results demonstrated that water depth explained large variations (53-64\%) in abundance in all three living habitat types, whereas height merely explained relatively few proportions
(21-40\%) of variations in abundance in all three living habitat types (Figure 4).

There was no correlation between floral sex ratio and seed quantity, water depth, or plant height. Among the seven sites, 
TABLE 2 | The relationships between species abundance and both demographic traits (photosynthetic rate, leaf proline content, and seed germination rate) and water depth, while accounting for the random effect of living habitat types (paddyfield, stream, and spring) tested using the linear mixed-effect model [formula: abundance $\sim$ trait/water depth $+(1 \mid$ living habitat type)].

\begin{tabular}{|c|c|c|}
\hline \multicolumn{3}{|l|}{ Source } \\
\hline \multirow[t]{4}{*}{ Height } & Degree of freedom & 1 \\
\hline & Effect size & 19.34 \\
\hline & $\boldsymbol{F}$ & 9.45 \\
\hline & $P$ & $<0.05$ \\
\hline \multirow[t]{4}{*}{ Water depth } & Degree of freedom & 1 \\
\hline & Effect size & 20.52 \\
\hline & $\boldsymbol{F}$ & 21.15 \\
\hline & $\boldsymbol{P}$ & $<0.05$ \\
\hline \multirow[t]{4}{*}{ Leaf area } & Degree of freedom & 1 \\
\hline & Effect size & 17.93 \\
\hline & $F$ & 1.24 \\
\hline & $P$ & $>0.05$ \\
\hline \multirow[t]{4}{*}{ Ratio of numbers of male and female flowers } & Degree of freedom & 1 \\
\hline & Effect size & 19.79 \\
\hline & $F$ & 0.46 \\
\hline & $P$ & $>0.05$ \\
\hline \multirow[t]{4}{*}{ Seed numbers } & Degree of freedom & 1 \\
\hline & Effect size & 20.42 \\
\hline & F & 0.84 \\
\hline & $P$ & $>0.05$ \\
\hline
\end{tabular}

The degree of freedom, effect size, F-statistics, and corresponding P-values are shown and boldface type indicates significant differences at $P<0.05$.

the floral sex ratio of Ding'an Cold Spring was the highest, while that of Xihu Niang Temple Spring was the lowest. Therefore, the floral sex ratio was not related to habitat type but might be related to spatial distribution distance. The highest number of seeds was in the stream of Chengmai Yongfa Town and stream of Nayang Village, while the lowest number of seeds was in the stream of Yangshan forest, indicating that the muddy substrate was favorable for seed production.

\section{DISCUSSION}

Hereby using monthly variations in abundance, some key demographic traits (height, leaf area, the ratio of numbers of male and female flowers, and seed numbers), and water depth, our results show the population dynamics of $O$. cordata and its influencing factors. Results show that although water depth and demographic trait (height) could affect the abundance, water depth and height had different predictive abilities in the abundance of $O$. cordata.

Demographic traits may directly reflect $O$. cordata performance as determined by growth, reproduction, and photosynthesis rate. For example, height has been shown to be highly associated with growth rate (Falster and Westoby, 2003; Sun and Frelich, 2011; Han et al., 2018). Similarly, previous studies indicate that the ratio of the male and female flowers and seed numbers are good indicators of plant reproductive ability of submerged macrophyte (Xu et al., 2015; Liu et al., 2017). In addition, leaf area could influence plant photosynthesis rate, with a large leaf area resulting in a high photosynthesis rate (Fu et al., 2014; Huang et al., 2020; Zhang et al., 2020). It had been found that growth, reproduction, and photosynthesis rate could determine plant abundance (Westoby et al., 1999; Wright et al., 2004; Zhang et al., 2013, 2018b). Thus, the relationship between abundance and these functional traits could provide insight into which characteristics may determine abundance for $O$. cordata. Since only height showed consistent and monthly variations with those for abundance, it is possible that only plant height is highly related to abundance. Indeed, we found that height was significantly and positively associated with abundance in all three living habitat types, whereas the other three demographic traits (the ratio of the numbers of male flowers and numbers of female flowers, leaf area, and seed numbers) were not significantly related with abundance. This suggests that growth rate, but not photosynthesis rate or reproduction, could determine abundance for O. cordata. Dynamics for abundance and demographic traits have been widely reported for many submerged macrophytes (Santamaría et al., 2003; Boedeltje et al., 2008; Fu et al., 2014; Bai et al., 2015). However, our results for the first time revealed that demographic traits could be used to predict abundance for submerged macrophytes. In addition, the number of plants per unit area was correlated with turbidity, and the number of plants per unit area was less when turbidity was higher. The water with high turbidity was usually a muddy substrate (there were more seeds on the muddy substrate) but fever plants per unit area, indicating that water quality may affect the growth and development of $O$. cordata.

It has been widely reported that water depth may determine both the abundance and biomass of submerged macrophyte (Xu et al., 2015; Li et al., 2017; Zhang et al., 2020). Here, we observed that water depth and abundance for $O$. cordata had varying consistently from month to month. Thus, water depth should be highly associated with abundance. Indeed, we observed that water depth was significantly and positively related to abundance in paddyfield and spring habitats, but negatively associated with abundance in the stream habitat owing to streams having the shallowest depths (all less than $45 \mathrm{~cm}$ ). These results indicate that water depth in paddyfields and springs could facilitate the re-establishment of $O$. cordata. In contrast, water depth in the streams would limit the population development of $O$. cordata. The key reason was that the distribution of $O$. cordata had a significantly dry and wet season, which in turn would lead to a significant alteration in water depth. It had been found that significant variation in water depth could facilitate growth and reproduction, which in turn would affect abundance and biomass for O. cordata. Thus, water depth could facilitate the population development and re-establishment of $O$. cordata. Here, we found that the paddyfield and spring water depth showed significant variations, with the highest and lowest water depth occurring in wet (September-November) and dry (March) seasons, respectively. Thus, it is not surprising to see the significantly positive water depth-abundance relationships in paddyfield and spring habitats. However, water depth in the stream habitat was relatively invariable across wet and dry 


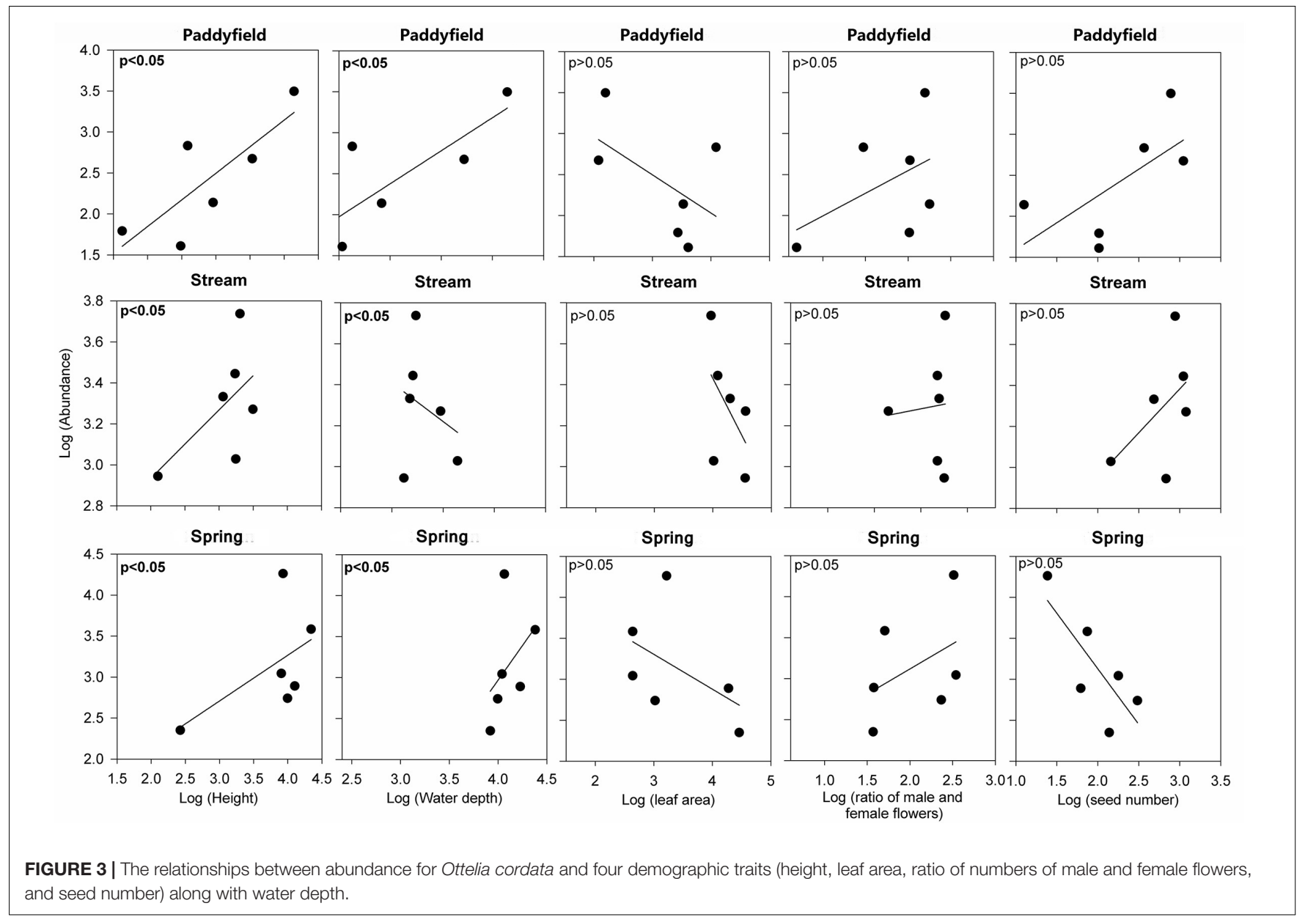

FIGURE 3 | The relationships between abundance for Ottelia cordata and four demographic traits (height, leaf area, ratio of numbers of male and female flowers, and seed number) along with water depth.

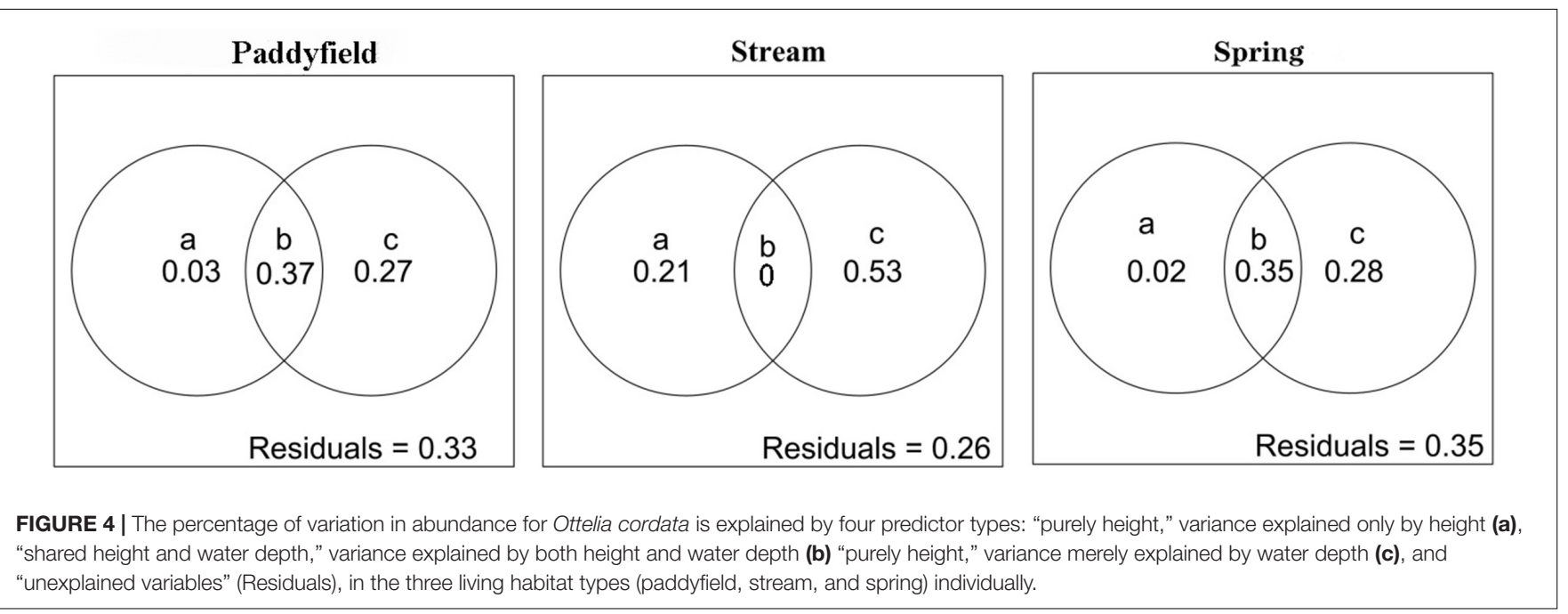

seasons. This is likely due to the previous unreasonable land use (i.e., deforestation, building apartment, and dam construction) causing serious wetland destruction, which in turn restricted the water depth (Wang et al., 2019). Here, the water depth would restrict population development and re-establishment of $O$. cordata thereby resulting in negative water depth-abundance relationships. However, deeper water would weaken the light and increase the sediment, which is also not conducive to the growth and reproduction of $O$. cordata and restricted the development of the population, similar to previous findings of aquatic plants (Kosuge et al., 2013). In addition, the height of O. cordata must be equal to or greater than the depth of water to produce 
floating leaves, which are the main organs for photosynthesis (Huang et al., 2020), and the stem must be out of the water to reproduce. In this study, when the water depth was close to $100 \mathrm{~cm}$, the number of seeds would be significantly reduced and the abundance of $O$. cordata decreased. Of course, only 1 of the 38 distribution points could reach $100 \mathrm{~cm}$ in the wet season, so shallow water depth was still the most important factor limiting the restoration and reconstruction of $O$. cordata.

Usually, submerged macrophytes would alter their height in response to the variations of water depth (Carollo et al., 2005; Li et al., 2017, 2020; He et al., 2019; Su et al., 2019). Thus, water depth should have a higher predictive ability of abundance than plant height. Indeed, our variance partition results indicated that water depth could explain a large proportion, while the height can only explain very little. As a result, water depth but not height could determine the abundance of $O$. cordata. Our results also showed that water depth and height were highly correlated in living habitats (paddyfield and spring), indicating that water depth mediated the influence of growth rate on the abundance of $O$. cordata in these habitats. However, water depth and height were not significantly correlated in the stream habitat suggesting that the limited water depth did not obviously affect plant growth. Thus, water depth tends to directly limit $O$. cordata population development. Therefore, it is incredibly important to restore the degraded wetland to retrieve the restricted water depth, otherwise O. cordata may have a high risk of going extinct.

\section{CONCLUSION}

Our results show the dynamics in abundance and demographic traits of $O$. cordata. We have clearly demonstrated that water depth and growth rate indicated by height could affect the abundance of $O$. cordata, but water depth plays a determining role. The floral sex ratio and fruit dynamic change were not directly related to water depth; instead seem to have effects on the sex ratio and whether it is the influence requires further study. In addition, the number of seeds in mud substrates was significantly

\section{REFERENCES}

Bai, X., Chen, K. N., Zhao, H. G., and Chen, X. M. (2015). Impact of water depth and sediment type on root morphology of the submerged plant Vallisneria natans. J. Freshwater Ecol. 30, 75-84. doi: 10.1080/02705060.2014.970672

Bates, D., Maechler, M., Bolker, B., and Walker, S. (2014). Ime4: Linear mixedeffects models using Eigen and S4. R package version 1.1-7. Available online at: http://CRAN.R-project.org/package=lme4 (accessed date 2021-06-22).

Boedeltje, G., Qzinga, W. A., and Prinzing, A. (2008). The trade-off between vegetative and generative reproduction among angiosperms influences regional hydrochorous propagule pressure. Glob. Ecol. Biogeogr. 17, 50-58. doi: 10.1111/ j.1466-8238.2007.00365.x

Carollo, F. G., Ferro, V., and Termini, D. (2005). Flow Resistance Law in Channels with Flexible Submerged Vegetation. J. Hydraul. Eng. 131, 554-564. doi: 10. 1061/(ASCE)0733-94292005131:7(554)

Curtis, R. J., Brereton, T. M., Dennis, R. L. H., Carbone, C., and Isaac, N. J. B. (2015). Butterfly abundance is determined by food availability and is mediated by species traits. J. Appl. Ecol. 52, 1676-1684. doi: 10.1111/1365-2664.12523 higher than that in sand substrates, but the number of plants per unit area in mud substrates was significantly lower than that in sand substrates. Because water turbidity in mud base was often higher, turbidity was also one of the factors causing the O. cordata to be endangered. Therefore, the restoration of wetland water quality should be strengthened. In conclusion, the abundance of $O$. cordata was limited by the relatively constant water depth due to wetland structure. Therefore, maintaining appropriate water depth levels $(30-90 \mathrm{~cm})$ or transplanting O. cordata to spring habitats may be a feasible and effective strategy to avoid potential harm to its abundance because the water is not only deep enough but also clear in spring habitats. However, in the long-term, it is critical that the whole degraded wetland in Yangshan Wetland Reserve to the wetland population gradually recover. For example, wetland water sources are managed to reduce water pollution, silt is removed to keep water quality clean (turbidity $\leq 10 \mathrm{NTU}$ ), and dredging systems strengthen connections between distribution points.

\section{DATA AVAILABILITY STATEMENT}

The original contributions presented in the study are included in the article/supplementary material, further inquiries can be directed to the corresponding author/s.

\section{AUTHOR CONTRIBUTIONS}

YS and XS designed the research and wrote the manuscript. YS and JL performed the research. YS and MR analyzed the data. All authors contributed to the article and approved the submitted version.

\section{FUNDING}

This work was funded by the Natural Science Foundation of Hainan Province (318MS010), China.

Davies, K. F., Margules, C. R., and Lawrence, J. F. (2000). Which traits of species predict population declines in experimental forest fragments? Ecology 81, 14501461. doi: 10.1890/0012-96582000081[1450:WTOSPP]2.0.CO;2

Dong, B. L., Qin, B. Q., Gao, G., and Cai, X. L. (2014). Submerged macrophyte communities and the controlling factors in large, shallow Lake Taihu (China): Sediment distribution and water depth. J. Great Lakes Res. 40, 646-655. doi: 10.1016/j.jglr.2014.04.007

Falster, D. S., and Westoby, M. (2003). Plant height and evolutionary games. Trends Ecol. Evol. 18, 337-343. doi: 10.1016/S0169-5347(03)00061-2

Fu, H., Zhong, J., Yuan, G., Ni, L., Xie, P., and Cao, T. (2014). Functional traits composition predict macrophytes community productivity along a water depth gradient in a freshwater lake. Ecol. Evol. 4, 1516-1523. doi: 10.1002/ece3.1022

Han, L., Yang, G., Yang, H., Xu, B., Li, Z., and Yang, X. (2018). Clustering Field-Based Maize Phenotyping of Plant-Height Growth and Canopy Spectral Dynamics Using a UAV Remote-Sensing Approach. Front. Plant Sci. 9:1638. doi: $10.3389 /$ fpls.2018.01638

He, L., Zhu, T., Wu, Y., Li, W., Zhang, H., Zhang, X., et al. (2019). Littoral Slope, Water Depth and Alternative Response Strategies to Light Attenuation Shape 
the Distribution of Submerged Macrophytes in a Mesotrophic Lake. Front. Plant Sci. 10:169. doi: 10.3389/fpls.2019.00169

Huang, W., Han, S., Xing, Z., and Li, W. (2020). Responses of Leaf Anatomy and $\mathrm{CO}_{2}$ Concentrating Mechanisms of the Aquatic Plant Ottelia cordata to Variable CO ${ }^{2}$. Front. Plant Sci. 11:1261. doi: 10.3389/fpls.2020.01261

Kosuge, K., Iida, S., Katou, K., and Mimura, T. (2013). Circumnutation on the water surface: Female flowers of Vallisneria. Sci. Rep. 3:1133. doi: 10.1038/srep01133

Legendre, P., Mi, X., Ren, H., Ma, K., Yu, M., Sun, I. F., et al. (2009). Partitioning beta diversity in a subtropical broad-leaved forest of China. Ecology 90, 663-674. doi: $10.1890 / 07-1880.1$

Li, H., Li, Q., Luo, X., Fu, J., and Zhang, J. (2020). Responses of the submerged macrophyte Vallisneria natans to a water depth gradient. Sci. Total Environ. 701:134944. doi: 10.1016/j.scitotenv.2019.134944

Li, L., Bonser, S. P., Lan, Z., Xu, L., Chen, J., and Song, Z. (2017). Water depth affects reproductive allocation and reproductive allometry in the submerged macrophyte Vallisneria natans. Sci. Rep. 7:16842. doi: 10.1038/s41598-01716719-1

Liu, J., Lin, F., Shi, S., Ayi, Q., Liu, S., Zeng, B., et al. (2017). Effects of water level regulation on the seed germination and production of annual plant Xanthium sibiricum in the water-level-fluctuating-zone of Three Gorges Reservoir. Sci. Rep. 7:5056. doi: 10.1038/s41598-017-04599-4

Neel, M. C., Leidner, A., Haines, A., Goble, D. D., and Scott, J. M. (2012). By the numbers: How is recovery defined by the US Endangered Species Act? BioScience 62, 646-657. doi: 10.1525/bio.2012.62.7.7

Nõges, T., and Nõges, P. (1999). The effect of extreme water level decrease on hydrochemistry and phytoplankton in a shallow eutrophic lake. Hydrobiologia 408, 277-283. doi: 10.1007/978-94-017-2986-4_30

Oksanen, J., Blanchet, F. G., Kindt, R., Legendre, P., Minchin, P. R., and O'Hara, R. B. (2016). Vegan: community ecology package. $R$ package version. 2.4-0.Available online at: https://cran.r-project.org/web/packages/vegan/index. html (accessed date 2020-November-28).

Philbrick, C. T., and Les, D. H. (1996). Evolution of aquatic angiosperm reproductive systems. Bioscience 46, 813-826. doi: 10.2307/1312967

Rytwinski, T., and Fahrig, L. (2012). Do species life history traits explain population responses to roads? A meta-analysis. Biol. Conserv. 147, 87-98. doi: 10.1016/j. biocon.2011.11.023

Santamaría, L., Figuerola, J., Pilon, J. J., Mjelde, M., Green, A. J., de Boer, T., et al. (2003). Gornall. Plant performance across latitude: The role of plasticity and local adaptation in an aquatic plant. Ecology 84, 2454-2461. doi: 10.1890/020431

Schemske, D. W., Husband, B. C., Ruckelshaus, M. H., Goodwillie, C., Parker, I. M., and Bishop, J. G. (1994). Evaluating approaches to the conservation of rare and endangered plants. Ecology 75, 584-606. doi: 10.2307/1941718

Søndergaard, M., Johansson, L. S., Lauridsen, T. L., Jørgensen, T. B., Liboriussen, L., and Jeppesen, E. (2010). Submerged macrophytes as indicators of the ecological quality of lakes. Freshwater Biol. 55, 893-908. doi: 10.1111/j.1365-2427.2009. 02331.x

Soudzilovskaia, N. A., Elumeeva, T. G., Onipchenko, V. G., Shidakov, I. I., Salpagarova, F. S., Khubiev, A. B., et al. (2013). Functional traits predict relationship between plant abundance dynamic and long-term climate warming. P. Natl. Acad. Sci. USA. 110, 18180-18184. doi: 10.1073/pnas. 1310700110

Su, H., Chen, J., Wu, Y., Chen, J., Guo, X., Yan, Z., et al. (2019). Morphological traits of submerged macrophytes reveal specific positive feedbacks to water clarity in freshwater ecosystems. Sci. Total Environ. 684, 578-586. doi: 10.1016/ j.scitotenv.2019.05.267

Sun, S., and Frelich, L. E. (2011). Flowering phenology and height growth pattern are associated with maximum plant height, relative growth rate and stem tissue mass density in herbaceous grassland species. J. Ecol. 99, 991-1000. doi: 10. 1111/j.1365-2745.2011.01830.x
Tear, T. H., Scott, J. M., Hayward, P. H., and Griffith, B. (1993). Status and prospects for success of the Endangered Species Act: A look at recovery plans. Science 262, 976-977. doi: 10.1126/science.262.5136.976

Wang, H.-X., Guo, J.-L., Li, Z. M., and Yu, Y.-H. (2019). Characterization of the complete chloroplast genome of an endangered aquatic macrophyte, Ottelia cordata (Hydrocharitaceae). Mitochondrial DNA B 4, 1839-1840. doi: 10.1080/ 23802359.2019.1612719

Wang, Q. F., Guo, Y. H., Haynes, R. R., and Hellquist, C. B. (2010). "Hydrocharitaceae," in Flora of China, eds Z. Y. Wu, R. H. Peter, and D. Y. Hong (Beijing: Science Press), 91-102.

Westoby, M., Eldridge, D., and Freudenberger, D. (1999). "The LHS strategy scheme in relation to grazing and fire," in Proceed-ings of the International Rangeland Congress, Vol. 2, (Townsville), 893-896.

Wright, I. J., Reich, P. B., Westoby, M., Ackerly, D. D., Baruch, Z., Bongers, F., et al. (2004). The worldwide leaf economics spectrum. Nature 428, 821-827. doi: 10.1038 /nature 02403

Xu, W., Hu, W., Deng, J., Zhu, J., and Li, Q. (2015). How do water depth and harvest intensity affect the growth and reproduction of Elodea nuttallii (Planch.) St. John? J. Plant Ecol. 9, 212-223. doi: 10.1093/jpe/ rtv048

Zhang, H., Chen, H. Y. H., Lian, J., John, R., Ronghua, L., Liu, H., et al. (2018a). Using functional trait diversity patterns to disentangle the scale-dependent ecological processes in a subtropical forest. Funct. Ecol. 32, 1379-1389. doi: $10.1111 / 1365-2435.13079$

Zhang, H., Gilbert, B., Zhang, X., and Zhou, S. R. (2013). Community assembly along a successional gradient in sub-alpine meadows of the QinghaiTibetan Plateau, China. Oikos 122, 952-960. doi: 10.1111/j.1600-0706.2012. 20828.x

Zhang, H., John, R., Zhu, S., Liu, H., Xu, Q., Qi, W., et al. (2018b). Shifts in functional trait-species abundance relationships over secondary subalpine meadow succession in the Qinghai-Tibetan Plateau. Oecologia 188, 547-557. doi: 10.1007/s00442-018-4230-3

Zhang, Q., Shen, Z., Li, F., and Li, G. (2019). Complete chloroplast genome sequence of an endangered Ottelia cordata and its phylogenetic analysis. Mitochondrial DNA B 5, 2209-2210. doi: 10.1080/23802359.2020.1768921

Zhang, X., Guo, K., Lu, C., Awais, R. M., Jia, Y., and Zhong, L. (2020). Effects of origin and water depth on morphology and reproductive modes of the submerged plant Vallisneria natans. Glob. Ecol. Conserv. 24:e01330. doi: 10. 1016/j.gecco.2020.e01330

Zhu, G. R., Li, W., Zhang, M., Ni, L. Y., and Wang, S. R. (2012). Adaptation of submerged macrophytes to both water depth and flood intensity as revealed by their mechanical resistance. Hydrobiologia 696, 77-93. doi: 10.1007/s10750012-1185-y

Conflict of Interest: The authors declare that the research was conducted in the absence of any commercial or financial relationships that could be construed as a potential conflict of interest.

Publisher's Note: All claims expressed in this article are solely those of the authors and do not necessarily represent those of their affiliated organizations, or those of the publisher, the editors and the reviewers. Any product that may be evaluated in this article, or claim that may be made by its manufacturer, is not guaranteed or endorsed by the publisher.

Copyright $(2021$ Shen, Lei, Song and Ren. This is an open-access article distributed under the terms of the Creative Commons Attribution License (CC BY). The use, distribution or reproduction in other forums is permitted, provided the original author(s) and the copyright owner(s) are credited and that the original publication in this journal is cited, in accordance with accepted academic practice. No use, distribution or reproduction is permitted which does not comply with these terms. 